artigo ] VOLUME 10 | NÚMERO 21 | MAIO 2017

[JULIA ATROCH DE QUEIROZ E MARIA ALICE VASCONCELOS ROCHA]

Mestre em Consumo, Cotidiano e Desenvolvimento Social pela Universidade Federal Rural de Pernambuco. E-mail: julia.atroch@gmail.com

Ph.D em Fashion Design; líder do Grupo de Pesquisa PLURAL - Moda e Vestuário; docente dos PPG em Design (UFPE) e PPG em Consumo, Cotidiano e Desenvolvimento Social (UFRPE).

E-mail: modalice.br@gmail.com

\title{
A relação dos consumidores com as inovações têxteis conduzidas pela nanotecnologia
}

\section{Consumer relationship with textile innovations conducted by nanotechnology}

[resumo] A nanotecnologia empregada nos tecidos e no vestuário vem permitindo o desenvolvimento e/ou a melhoria de novas propriedades têxteis, porém, a relação dos consumidores com essas novidades ainda precisa ser estudada. Sabe-se que tais aspectos estão associados à eficácia do produto, a fatores econômicos e a condições culturais, sociais e ambientais. Posto isso, o objetivo deste artigo foi investigar a opinião dos consumidores sobre o conteúdo nanotecnológico de tecidos e roupas com valor de moda. Para tanto, foi realizada uma pesquisa qualitativa que usou a técnica de focus group para coletar os dados. Assim, entre os resultados deste estudo, é possivel observar o conceito de nanotecnologia percebido, os benefícios associados a ele e a relação entre riscos e benefícios para os consumidores.

[palavras-chave]

inovação; nanotecnologia; percepção.

[abstract] Nanotechnology used to textiles and clothing comes enabling the development and/or improvement of new textile properties, however, the consumer relationship with these innovations need to be further studied. It is known that such aspects are associated to the product's effectiveness, economic factors, cultural, social and environmental conditions. That said, the objective of this paper was to investigate the opinion of consumers about the content of nano-fabrics and clothes with fashion value. It was performed a qualitative research that used the focus group technique to collect the data. Thus, among the results of this study it is possible to observe the concept of nanotechnology perceived; the benefits associated with it and the relationship of the risks with the benefits to consumers.

[keywords] innovation; nanotechnology; perception. 


\section{Introdução}

As transformações da sociedade impulsionaram uma busca inevitável por melhorias na qualidade percebida nos produtos industriais. Isso porque, hoje, satisfazer a necessidade do consumidor não depende apenas da qualidade técnica que um produto pode the oferecer, mas também da capacidade desses produtos em significar algo para o usuário final, isto é, comunicar-se (CARDOSO, 2012; SOLOMON, 2011; NORMAN, 2008).

Segundo Niemeyer (2009), no fim do século passado, a importância da significação ganhou crescente relevância no desenvolvimento de alguns projetos de produtos. Nesse sentido, os itens não são vistos apenas por meio da elaboração técnica da produção industrial que objetiva a atividade prática do consumidor, mas como expressão cultural de um individuo ou de uma sociedade. Para Norman (2008), os objetos que estão presentes na vida de cada indivíduo são mais do que meros bens materiais. Eles são motivo de orgulho, não necessariamente porque exibem riquezas e status, mas, principalmente, porque conseguem dar sentido à vida das pessoas.

Inserida nesse contexto, a nanotecnologia usada para desenvolver artefatos têxteis com valor de moda vem ganhando cada vez mais destaque no processo de inovação das empresas de tecidos e de confecção do vestuário. Contudo, apesar da constante pesquisa e do desenvolvimento da capacidade técnica desse processo, o estudo sobre as relações dessa nova tecnologia com os consumidores ainda é bastante escasso. Sabe-se que tal informação é fundamental para a consolidação do processo de inovação e, consequentemente, para a satisfação dos consumidores (SENAI-SP, 2012; SOLOMON, 2011; SAWHNEY et al., 2008; COLCHESTER, 2007).

Para tanto, o propósito principal deste artigo é investigar a opinião dos consumidores sobre o conteúdo nanotecnológico de tecidos e roupas com valor de moda. Especificamente, os objetivos desta pesquisa incluem identificar o conceito de nanotecnologia a partir dos consumidores, nomear os benefícios percebidos pelos consumidores associados à aplicação da nanotecnologia nos têxteis e caracterizar a relação entre riscos e benefícios estabelecida pelos consumidores.

Assim, com base na abordagem teórica apresentada por Rocha (2012), Bürdek (2010), Löbach (2001), Gomes Filho (2006), Medeiros, Paterno e Mattoso (2006), entre outros, foi desenvolvida uma pesquisa qualitativa de natureza exploratória que contou com a técnica de discussões em grupo focal a fim de se obter as informações necessárias para a realização deste artigo.

\section{A nanotecnologia na indústria têxtil e de confecção do vestuário}

Atualmente, as indústrias têxteis dispõem de uma enorme variedade de tecnologias, isto é, processos, máquinas, fibras, fios e substâncias para acabamentos com os quais produzem tecidos com caracteristicas inovadoras, que promovem maior desempenho ao usuário e demandam uma manutenção mais fácil. Essas funções são obtidas graças à descoberta de que propriedades especificas podem ser produzidas a partir da manipulação de partículas em escalas nanométricas (FRINGS, 2012; SAWHNEY et al., 2008; UDALE, 2009; PEZZOLO, 2007; LAVER, 2003).

A nanotecnologia é a atividade de explorar as caracteristicas dos materiais e sistemas, cuja "estrutura e componentes exibem propriedades e fenômenos físicos, químicos e/ou biológicos significativamente novos e modificados devido à sua escala" (MEDEIROS; PATERNO; MATTOSO, 2006, p. 20), para fabricar e/ou usar esses dispositivos de forma eficiente.

Atualmente, o domínio da nanotecnologia encontra-se entre 1 e 100 nanômetros, dimensão equivalente ao comprimento de uma fila de 5 a 10 átomos. 0 intervalo foi estabelecido porque essa tecnologia é incluída apenas dentro 
de espectros nos quais fenômenos da física clássica não se aplicam e, ao mesmo tempo, os da física quântica se manifestam. Assim, é válido ressaltar que o limite de $100 \mathrm{~nm}$ é fluido, pois existe a possibilidade de trabalhar com dimensões ainda maiores (por exemplo, $200 \mathrm{~nm}$ ) nas quais esse fenômeno aparece (SENAI-SP, 2013; FLLIPPONI, SUTHERLAND, 2012).

A quebra da partícula para deixá-la com a dimensão nano permite que os efeitos quânticos - caracterizados pela mudança de importância das forças fundamentais da natureza, como a gravidade, o atrito e a eletrostática, bem como pela manifestação de novos fenômenos, como o de Van der Waals 1 e o movimento browniano - passem a ser determinantes sobre a matéria (MEDEIROS; PATERNO; MATTOSO, 2006).

Desse modo, a inovação por intermédio da nanotecnologia consiste na manufatura de novos produtos simplesmente por meio da redução do tamanho do material que deverá ser manipulado e/ou estruturado, ou seja, gerar novas propriedades sem alterar a composição química de uma substância (SENAI-SP, 2013; MEDEIROS; PATERNO; MATTOSO, 2006).

0 interesse do setor têxtil e de confecções pelos benefícios criados graças aos fenômenos quânticos, que atuam nas nanopartículas, tem crescido nos últimos anos. Isso porque, entre outros aspectos, eles acarretam elevada durabilidade no que diz respeito às novas funções aplicadas aos têxteis, na medida em que as funções já existentes costumavam perder o efeito após algumas lavagens ou por causa do uso (AHMED, EL-SHISHTAWY, 2010).

LST (2015); Prata e Gouda (2013) e Apel et al. (2013) esclarecem que as novas gerações de materiais podem ser classificadas como:

Nanopartículas - são fragmentos de uma matéria que se encontram em uma escala de aproximadamente $1 \mathrm{~nm}$ a $100 \mathrm{~nm}$.

Nanoestrutura - materiais cuja estrutura interna ou de superficie encontra-se com dimensões nanométricas.

Nanocompósitos - consistem na mistura, em escala nano, de um ou mais componentes para compor uma substância na qual cada elemento deverá ter o seu desempenho melhorado.

Nanofibras - são caracterizadas como fibras que possuem um diâmetro inferior a $1 \mu \mathrm{m}$, geralmente produzidas por meio do método electrospinning?

De acordo com Hossain et al. (2013), apesar da indústria têxtil e de confecção estar no início de suas pesquisas e desenvolvimento de materiais por meio da nanotecnologia, já é possivel afirmar que esta trouxe acabamentos inovadores para os produtos desse setor, além de contribuir para a elaboração de novas técnicas de produção e aplicação de materiais e/ou nanomateriais. Segundo demonstraram os autores, o conhecimento produzido por meio da investigação e do uso dessa tecnologia permite que processos de acabamentos químicos controláveis e mais minuciosos passem a ser preferenciais na aplicação de nanomateriais em tecidos e vestuário, fato que deverá, no futuro, gerar maior qualidade e baixo custo para empresas que investem nessa tecnologia.

Os métodos relacionados aos processos de acabamentos convencionais, ou seja, impregnação com ajuda de equipamentos de enchimento, pulverização ou impressão, entre outras técnicas, são uma das mais potenciais aplicações dos nanomateriais em tecidos e vestuário, os quais estão, em geral, no formato de nanoemulsões e nano-sóis (JOSHI, BHATTACHORYYA, 2015; OECD, 2004).

Assim, o desenvolvimento da nanotecnologia e, consequentemente, dos nanoacabamentos, permite que artefatos têxteis incorporem funções antimicrobiana, 
proteção para a pele contra raios ultravioleta (UV), resistência a água e óleo, antimanchas, cosméticas, entre outras. Nesse sentido, elas já estão disponiveis para o consumidor final (DENG; ZHANG, 2015; ZILLE et al., 2014; WINDLER; HEIGHT; NOWACK, 2013; BROASCA et al., 2013; FERREIRA, 2013; ALMEIDA et. al., 2012; ROSA E COSTA, 2012; JOSHI; BHATTACHARYYA, 2011).

0 emprego da nanotecnologia no desenvolvimento de novos materiais é recente, contudo, os estudos envolvendo partículas nanométricas "[...] andam em uma velocidade espantosa em busca da maturidade [...]" (SENAI-SP, 2013, p. 21). Porém, a compreensão sobre a percepção dos consumidores em relação à nanotecnologia deve ser ampliada para que essa inovação atenda às necessidades da indústria e dos consumidores sem deixar de considerar os impactos positivos e/ou negativos que podem causar na sociedade (FLAIN, 2011).

Para fins deste estudo, define-se como percepção o processo pelo qual as pessoas selecionam, organizam e atribuem significado às sensações causadas pelos receptores sensoriais a estímulos, como imagens, sons, odores, gostos e texturas. Considera-se que os significados atribuidos a essas sensações sejam o resultado de um processo de aprendizagem consolidado em dois aspectos fundamentais: a objetivação dos processos e os significados subjetivos (SOLOMON, 2009; BERGER; LUCKMANN, 2004).

0 primeiro refere-se à organização dos objetos presentes nos mundos físico e subjetivo de cada pessoa ou sociedade, sendo importante ressaltar que esses objetos podem fazer parte de diferentes realidades, isto é, pertencer a diversos tipos de experiência ou estruturas de significados. 0 segundo consiste na interiorização dos sentidos por determinada pessoa ou sociedade, podendo ocorrer por meio da apreensão ou da interpretação imediata de um acontecimento objetivo que expressa algum sentido para outrem. Nessa construção social, que é uma prática, como a própria dialética, forma-se o mundo intersubjetivo (BERGER; LUCKMANN, 2004).

Em relação a esse aspecto, é possivel destacar também que o significado, ou seja, "a produção humana de sinais" (BERGER; LUCKMANN, 2004, p. 47), é um caso especial das objetivações que, ao se agruparem em certo número de sistemas, tornam-se expressões subjetivas da sociedade.

Portanto, para compreender a maneira como o consumidor percebe a nanotecnologia é necessário atentar, de forma dialética, para os aspectos que interferem no processo de aprendizagem dos consumidores. Essa preocupação resultará no desenvolvimento de estratégias de comunicação para a aceitação da nova tecnologia têxtil, visto que há uma precedência do conhecimento sobre os valores do indivíduo (SALCEDO, 2014; ENGEL; BLACKWELL; MINIARD, 2005; BERGER; LUCKMANN, 2004).

0 estudo do comportamento do consumidor deve ajudar a desenvolver as estratégias para que uma nova ideia seja aceita por uma sociedade. Para isso, esta área de conhecimento preocupa-se em estudar os "[...] processos envolvidos quando individuo ou grupo de pessoas selecionam, compram, usam ou descartam um produto, serviço, ideia ou experiência para satisfazer necessidades e desejos" (SOLOMON, 2011, p. 33). Os resultados desse conhecimento são fundamentais para estabelecer os tipos de mercado para qual um determinado produto ou serviço será ofertado e desenvolver estratégias de comunicação para um grupo de consumidores, ou seja, as implicações desse tipo de estudo são essenciais para estabelecer uma relação de fidelidade com os consumidores e, consequentemente, obter maior competitividade (SOLOMON, 2011).

A elaboração de estratégias de aceitação da nanotecnologia ajudará a construir a qualidade percebida do artefato têxtil desenvolvido por meio da nanotecnologia, ou seja, ela elabora ferramentas que interferem no julgamento global 
de um objeto pelo consumidor, sobre a maneira como ele busca atender às suas expectativas (LIMA; STEINER NETO, 2014; ARRILLAGA; GAND; RAMÍREZ, 2013; SOLOMON, 2011).

Sendo assim, a qualidade não está limitada à percepção do bom desempenho operacional e funcional do produto final, mas está, principalmente, associada à capacidade de esses artefatos expressarem os valores do consumidor. A compreensão dessa perspectiva é um aspecto fundamental para o desenvolvimento de elementos que permitam a uma nova ideia tornar-se de fato inovação, ou seja, que uma mudança significativa passe a ser validada pelo mercado (ARRILLAGA; GAND; RAMÍREZ, 2013, p. 122; CARDOSO, 2012; SOLOMON; 2009).

A tática para alcançar a validação de uma inovação deve considerar que toda ação humana tem sua gênese na sua causalidade. Todavia, o que se chama de posição ao fim, ou seja, a finalidade que determina a ação, é que vai estimular a descoberta de novas tecnologias, sendo esse momento teleológico a base da manifestação do valor (LESSA, 2012).

Lessa $(2012$, p. 120) esclarece que esse é o valor, um fenômeno puramente social, e pode ser descrito como o conjunto de

[...] qualidades objetivas potencialmente presentes no ser - precisamente - assim existente, potencialidade que apenas pode se atualizar no interior da relação teleologia/causalidade. Portanto, os valores nem são puramente subjetivos nem decorrências diretas da materialidade dos objetos, mas uma dimensão ontológica puramente social, inexistente na natureza, e que corresponde a um elemento essencial - certamente não o único - da nova objetividade que consubstancia o mundo dos homens. A essência dos valores para o mundo dos homens está em que, sem eles, não há atos teleologicamente postos, ou seja, sem eles não há ser social. Evidentemente, não estamos com isso afirmando que em Lukács o mundo dos homens possa ser reduzido aos valores.

Desse modo, Lessa (2012) descreve o valor como fenômeno caracteristico do ser historicamente construido e determinado por sua busca para satisfazer e/ou desenvolver uma utilidade para o mundo social, ou seja, visando um futuro posto. 0 autor considera que a manifestação desse fenômeno, chamada de processos valorativos, ocorre graças aos elementos da sociedade: a exterioridade e a individualidade. 0 primeiro pode ser interpretado como a ação de retorno dos valores e complexos valorativos sobre seu criador, ou seja, a atribuição de significados ao mundo no qual ele habita. 0 segundo é determinado pela experiência particular do individuo.

Por fim, Lessa (2012) considera que a existência desse fenômeno age mesmo quando não se eleva de fato a consciência do indivíduo, e só é possível dentro de um complexo organizado de uma sociedade. Ele ressalta que, na sociedade contemporânea, o sistema econômico é o elemento fundamental para a formação dos valores e processos valorativos.

Ainda sobre a inovação, é possível destacar que, quando ela é associada apenas à alteração significativa da técnica, com o propósito de rentabilidade da sua manufatura, é classificada por Schumpeter como inovação tecnológica. Entretanto, outras abordagens, apesar de considerarem a influência do apelo mercadológico para obter maior produtividade, tratam a inovação como "qualquer mudança, de consequências permanentes, na organização e/ou no modo de produção enfrentado por um grupo social"3. Porém, tais atividades não provêm da alteração da técnica, mas envolvem principalmente as modificações das práticas sociais. 
Nesse sentido, ela é denominada pelos autores como inovação social e refere-se a toda ideia e/ou transformação (onerosa ou não) que visa atender as necessidades sociais (ARRILLAGA; GAND; AMÍREZ, 2013, p. 122).

Dessa forma, introduzir um processo de inovação tem o propósito principal de melhorar o desempenho de uma organização e/ou de um produto que deverá ser oferecido aos consumidores. Portanto, assim como acontece com a tecnologia e a inovação, o desempenho de uma organização precisará ser avaliado com base em três aspectos: 0 econômico, o ambiental e o social (FELICE; PETRILLO, 2013).

No que tange a relação da avaliação de desempenho e o perfil de comportamento dos consumidores da indústria têxtil e de confecções, as quais alimentam o setor de moda, há uma tendência da preocupação com a trajetória da manufatura de um artefato, ou seja, com as condições de trabalho, envolvendo a produção e os impactos que as confecções desses produtos poderão causar no meio ambiente (SALCEDO, 2014).

Assim, oferecer transparência sobre o caminho adotado para a produção dos artefatos, destacando a preocupação com a humanização do trabalho e com o impacto que tal atividade poderá provocar no meio ambiente, é uma das estratégias que pode ser também caracterizada como inovação. Da mesma forma, as medidas adotadas para minimizar ou eliminar esses impactos, são adotadas por esse setor industrial quando em consonância com as novas demandas dos consumidores e com a melhoria do desempenho dessas organizações (SALCEDO, 2014).

Não é possivel esquecer que as novas tendências de comportamento dos individuos trouxeram também aspectos negativos, como o hiperconsumo e, consequentemente, a destruição ou a contaminação do meio ambiente por alimentar um modelo econômico complexo como o capitalismo. Contudo, muitos benefícios foram obtidos ao longo desse percurso impulsionados pela inovação tecnológica e social, como as novas tecnologias ligadas à saúde e ao conforto que o vestuário pode oferecer para o usuário. Dessa forma, cabe aos sujeitos dessa história encontrar, no processo de inovação, estratégias que proporcionem um maior desenvolvimento para a sociedade (ITMA, 2015; CRUZ, 2014; MANZINI, 2008; TERRA, BATISTA, ALMEIDA, 2010).

Posto isso, é possivel afirmar que as inovações têxteis conduzidas pela nanotecnologia devem considerar se existe algum impacto causado nos profissionais que desenvolvem esses novos materiais, no usuário final e no meio ambiente. Portanto, o desenvolvimento e o emprego de nanomateriais devem considerar o tamanho, a quantidade e o tipo de nanopartículas, além do tempo que elas permanecem no organismo dos usuários, levando em conta que a permanência prolongada ou a ausência da capacidade de biodegradação determinada por esses tipos de características poderão ser igualmente nocivas (SANTOS, 2012).

\section{A caracterização dos produtos têxteis e sua relação} com o processo de design

0 corpo humano faz um esforço automático para se manter em equilibrio (homeostase), provocando as necessidades, ou seja, um estado de agitação causado pelo desequilibrio do corpo que impulsiona a realização de atividades que podem ser influenciadas e/ou alteradas por fatores externos a cada pessoa (SOLOMON, 2011; LÖBACH, 2001; MASLOW, 1987 apud ROCHA, 1999).

Além das necessidades, Solomon (2011) destaca que, para ofertar produtos ou serviços que permitam ao indivíduo alcançar o seu estado de equilibrio, é necessário atentar também para os desejos do consumidor. Isso significa que é importante considerar o modo como o consumidor pretende suprir suas necessidades.

Considerando esse contexto, é possivel afirmar que o desenvolvimento e o consumo de artefatos têxteis têm estreita ligação tanto com as necessidades vestimentares fisicas quanto com as necessidades vestimentares psicológicas dos 
seres humanos. Assim, além da necessidade de proteção contra as intempéries da natureza, o adorno e o pudor são a base das motivações originais para o surgimento de roupas. Esses aspectos estão relacionados, respectivamente, à mudança sobre a percepção de higiene por meio do desenvolvimento cientifico; à necessidade de distinção da aparência física; e à aceitação, a qual está geralmente associada à busca por esconder as características físicas que podem afetar o destaque das pessoas dentro de um grupo (FLÜGEL, 1966).

0 primeiro aspecto, a proteção, refere-se à tangibilidade dos objetos, ou seja, menciona que "é plenamente possivel se fazer uso dos cinco sentidos humanos para caracterizar o tangivel: você vê, toca, cheira, ouve e degusta" (ROCHA, 2012, p. 6). Nesse caso, o que está sendo ressaltado é a função da vestimenta, a qual está diretamente ligada às necessidades corporais, como, por exemplo, conforto, higiene, segurança, mobilidade, etc.

Em seguida, os dois últimos elementos, as necessidades associadas ao pudor e ao adorno, podem ser classificados como aspectos intangíveis dos produtos têxteis e do vestuário. De acordo com Rocha $(2012$, p. 6):

A denominação intangível é atribuída por conta da natureza dos componentes deste aspecto, ou seja, nada é material, possível de ser sentido, mas impossível de ser tocado. [Nesse sentido] As tendências são sinais de alterações do comportamento coletivo; as atitudes são reações desencadeadas por ações; os valores são os significados que mais nos importam e o estilo de vida é a combinação de tudo que você crê com a maneira que você age no cotidiano.

Assim, é possivel afirmar que a moda é um elemento intangivel do objeto que influencia o processo de satisfação do ser sociedade e do ser indivíduo simultaneamente, isto é, oferece ao consumidor elementos que deverão eliminar o estado de agitação e retorná-lo a um estado de homeostase. Sabe-se ainda que as peças de vestuário são o meio mais significativo para as empresas estimularem o consumo de moda (ROCHA, 2012; SOLOMON, 2011; LIPOVETSKY, 2009).

Portanto, por mais influente que a marca associada a essas mercadorias seja, é sempre possível criar mais valor para elas. Logo, o estudo sobre a moda torna-se uma etapa fundamental para compreender o processo de valorização pelos consumidores (ROCHA, 2010; SOLOMON; RABOLT, 2004).

Contudo, é válido ressaltar que, para isso ocorrer, a indústria têxtil e de confecção do vestuário, que atende o mercado de moda, deverá realizar dois tipos de pesquisa para implementar o processo de inovação das tecnologias: a coleta de materiais tangiveis e práticos para sua coleção (como tecidos, aviamentos, etc.) e definir a inspiração visual que ajudará na definição dos aspectos intangíveis, como tema, inspiração ou conceito, que são fundamentais para construir a identidade de uma coleção. Portanto, deve-se investigar os elementos do objeto, bem como os significados atribuídos a ele, a fim de que esses produtos consigam emitir uma mensagem para o consumidor, ou seja, comunicar-se (FRINGS, 2012; SEIVEWRIGHT, 2012; LÖBACH, 2001).

Entre os elementos investigados, os tecidos são uma das mais importantes matérias-primas da indústria de moda que, assim como o vestuário com valor de moda, possuem aspectos tangiveis e intangiveis a serem investigados, para que os profissionais consigam integrar, no produto final, aspectos funcionais, estéticos e simbólicos descritos e/ou propostos no projeto de uma empresa (UDALE, 2009; PEZZOLO, 2007).

Identificar a função para a qual esses tecidos serão destinados, bem como conhecer suas qualidades estéticas (textura, cor, estampa, superficie e caimento) e a maneira como deverá ser manuseado pela indústria e pelos consumidores, são 
alguns dos elementos importantes para o desenvolvimento de inovações no setor têxtil que satisfaçam as necessidades e os desejos do consumidor. Além disso, é útil para a indústria da moda conhecer o desenvolvimento histórico do uso de tecidos, ou seja, quais os tipos de tecidos e técnicas que se tornaram importantes e influentes na moda ocidental (UDALE, 2009).

Assim, a indústria utiliza o processo de design com o propósito de entender essas informações e desenvolver atributos que melhorem a percepção do usuário em relação aos artefatos, promovendo uma interação do indivíduo com esses objetos de forma prazerosa, sem deixar de oferecer à empresa um bom desempenho organizacional, além de produtos de grande aceitação do mercado para o qual ele foi configurado. A elaboração dessas informações, ou seja, o desenvolvimento de produtos que se comunicam com o consumidor, ocorre por meio da configuração das seguintes funções: indicativa (prática), estética e simbólica (QUEIROZ, COUTINHO, ROCHA, 2013; BÜRDEK, 2010; LÖBACH, 2001; TREPTOW, 2007).

Dessa forma, é possivel considerar que as funções indicativas dizem respeito às características práticas dos produtos, isto é, a aspectos ligados à utilidade, como, por exemplo, seu manejo ou sua manipulação; as funções estéticas têm como objetivo tornar evidentes os aspectos práticos do produto, podendo, no entanto, ser, ao mesmo tempo, subordinada a aspectos socioculturais, bem como às impressões dos indivíduos sobre os produtos obtidas por meio de processos sensoriais decorrentes de interações com elementos formais do objeto, estes conseguidos durante o uso do produto; e as funções simbólicas são os aspectos espirituais, psíquicos e sociais associados a experiências e sensações anteriores capazes de transformar um objeto em símbolo (BÜRDEK, 2010; LÖBACH, 2001; GOMES FILHO, 2006).

0 símbolo pode ser definido como "um sinal que por meio de uma combinação (convenção) possui significado intercultural" (BÜRDEK, 2010, p. 322) que, em geral, acontece de forma associativa e nem sempre explícita. Contudo, é possível afirmar que a interpretação de um símbolo depende não só dos aspectos qualitativos ou físicos dos objetos, mas também do fato de receber, principalmente, influência do contexto no qual está inserido e de convenções socioculturais. A função simbólica de um produto de design deverá, portanto, vincular os mundos simbólicos dos consumidores ao dos produtores de símbolos (as empresas), mas, para isso, é indispensável compreender detalhadamente os respectivos mundos simbólicos.

Sobre o significado do objeto obtido mediante o estudo desses dois universos, ou seja, consumidores e produtores, o autor estabelece ainda que eles são determinados pelos diversos contextos nos quais podem ou deverão aparecer. Assim,

Tudo o que se sabe sobre ele ou se pode mencionar - história, processo de fabricação, círculo de usuários, lógica das funções, valor econômico - são transmitidos pela linguagem. [Portanto] estabelecer qual significado um produto deverá ter para o usuário é o propósito do processo de design. (BÜRDEK, 2010, p. 337)

Adicionalmente, Norman (2008) destaca que as estratégias projetuais devem considerar os diferentes tipos de estímulos produzidos pelo objeto. Segundo o autor, deve-se trabalhar levando em conta os três niveis: visceral, comportamental e reflexivo. 0 estímulo visceral corresponde às respostas decorrentes de componentes automáticos, os quais necessitam da compreensão dos padrões humanos de respostas automáticas instintivas para a elaboração das estratégias projetuais; o estímulo comportamental está ligado ao processo de aprendizagem e à cultura do indivíduo; e o reflexivo está associado principalmente aos significados que 
deverão ser projetados. Assim, deve-se considerar a autoimagem e a memória dos usuários como pontos de partida do projeto de um artefato.

Desse modo, sobre as funções comunicativas do objeto apresentadas neste texto até agora, é possivel entender que não só a função simbólica, mas também as indicativas e estéticas correspondem ao conjunto de conhecimento produzido ao longo da vida de cada individuo ou sociedade e, posteriormente, inscrito e transmitido por meio do desenvolvimento de novos artefatos. Portanto, para o desenvolvimento dos artefatos como instrumentos de comunicação, deve-se considerar "os diferenciados canais de percepção e recepção sensorial da informação pelo usuário e a respectiva capacidade de assimilação de seus canais receptores" (GOMES FILHO, 2006, p. 87).

\section{Metodologia}

Esta pesquisa é caracterizada como um estudo qualitativo de natureza exploratória por utilizar elementos, como teorias e/ou conceitos existentes, sobre nanotecnologia, além de incluir entrevistas realizadas com os consumidores a fim de cumprir o desígnio proposto (CRESWELL, 2003; GILL, 1987).

Assim, para a pesquisa de campo, foi empregada a técnica que utiliza a interação grupal com propósito de discutir e reunir informações detalhadas sobre um tema específico - à medida que o grupo recebe estímulos apropriados para tal debate (focus group). Nota-se que essa técnica ocupa uma posição intermediária entre a observação participante e a entrevista de profundidade, pois ela concede ao pesquisador não só o contato direto com o universo estudado, mas também Ihe permite observar fatos e conexões sobre 0 assunto estudado em seu contexto, quebrando barreiras subjetivas e/ou culturais geralmente responsáveis pela incompreensão dos dados coletados na pesquisa de campo (BARBOUR, 2009; RESSEL et. al, 2008; GONDIM, 2002).

Para aplicar a técnica, foram recrutados nove avaliadores-consumidores (cinco mulheres e quatro homens) residentes na região metropolitana do Recife (RMR/ Microrregião Recife): Abreu e Lima, Cabo de Santo Agostinho, Camaragibe, Jaboatão dos Guararapes, Moreno, Olinda, Paulista, Recife (IBGE, 2010).

0 perfil dos avaliadores-consumidores para o focus group foi extraído, em uma fase preliminar, de uma pesquisa feita com consumidores que adotou a ferramenta de investigação Survey, a qual, a partir dos requisitos apresentados por Babbie (2003), foi realizada por meio de um questionário composto por 18 perguntas objetivas e subjetivas sobre o perfil desses consumidores, assim como indagações a respeito da percepção e dos desejos dessas pessoas sobre os temas relacionados às tecnologias têxteis convencionais e à nanotecnologia aplicada aos tecidos e roupas. Portanto, a familiaridade com esses temas, ocasionada pelo conhecimento teórico e/ou experiência de uso, foi critério fundamental para a seleção dos avaliadores-consumidores.

0 convite para participar do focus group foi feito por e-mail, redes sociais, telefone e pessoalmente. Os avaliadores-consumidores foram reunidos em uma única sessão, coordenada por duas mediadoras imparciais e treinadas com antecedência. Ambos, avaliadores-consumidores e mediadores, foram recompensados com camisas beneficiadas com substância nanotecnológica4.

A sessão teve duração de duas horas e foi realizada na Universidade Federal Rural de Pernambuco, local onde os participantes se acomodaram em mesas individuais dispostas em forma de um semicírculo, para facilitar o diálogo ou a troca de experiências sobre o objeto analisado. Os diálogos foram gravados para posterior transcrição e análise pela pesquisadora. Assim, antes de se iniciarem os debates e as dinâmicas, foi importante que os integrantes do grupo focal lessem 0 termo de consentimento e, ao concordarem, assinassem, para que a pesquisa- 
dora pudesse utilizar os dados colhidos durante a sessão. Foi pactuado que todo o conteúdo discutido seria para uso exclusivo acadêmico e que seus nomes não seriam revelados.

$\mathrm{Na}$ ocasião, as mediadoras informaram também que não existia resposta certa ou errada a qualquer dos estímulos e discussões, portanto, o receio de falar algo deveria ser evitado e combatido, por mais que os participantes acreditassem que sua opinião não tinha importância ou que se tratava de alguma tolice. Assim, todas as opiniões foram postas para o grupo e não apenas para o colega ao lado, a fim de que nenhum participante deixasse de debater sobre 0 assunto tratado e novas perspectivas sobre o tema pudessem surgir e ser discutidas (BARBOUR, 2009; FLICK, 2009).

De acordo com Silverman (2009), o esclarecimento sobre as questões éticas, mencionadas no parágrafo anterior, é uma etapa fundamental da pesquisa social, pois deixa claro aos participantes a responsabilidade de quem realiza a pesquisa em relação às pessoas estudadas.

0 grupo focal participou de três dinâmicas: 1) integração do grupo por meio da análise de imagens; 2) análise sensorial, sem orientação sobre o conteúdo nanotecnológico das amostras de tecido; 3 ) análise sensorial com orientação sobre o conteúdo nanotecnológico das amostras de tecido. Cabe destacar aqui que este artigo corresponde a um extrato de trabalho de uma pesquisa maior, portanto, a descrição das dinâmicas que serão apresentadas a seguir corresponde a parte do que ocorreu na Dinâmica 3.

A dinâmica iniciou-se com uma breve explicação sobre o conteúdo da atividade e a apresentação do protocolo de manipulação tátil (Tabela 1).

\section{Tabela 1 - Protocolo de manipulação tátil entregue aos avaliadores}

\begin{tabular}{|l|l|}
\hline \multicolumn{2}{|l|}{ Protocolo de manipulação tátil } \\
\hline 1 & $\begin{array}{l}\text { Colocar a amostra de tecido em uma superfície plana e mover primeiro a palma } \\
\text { da mão e depois a parte de trás da mão na horizontal. }\end{array}$ \\
\hline 2 & Friccionar a amostra de tecido entre as pontas dos dedos polegar e indicador. \\
\hline 3 & Colocar a amostra de tecido na palma da mão e fechá-la para compressão. \\
\hline 4 & Segurar a amostra de tecido com as duas mãos e puxar. \\
\hline
\end{tabular}

Foram escolhidos cinco tipos de tecidos de diferentes composições, cada um formatado em retângulos iguais de $729 \mathrm{~cm}^{2}$. Porém, a malha supplex foi fracionada em quadradros com $225 \mathrm{~cm}^{2}$, pois o custo elevado desse artefato oneraria e inviabilizaria a sua análise caso fosse mantida a decisão de deixá-lo com o mesmo padrão dos demais tecidos, fato que não interferiu na percepção dos avaliadores sobre as amostras (Tabelas 2 e 3 ).

Posteriormente, as amostras foram encaminhadas para limpeza, amaciamento e aplicação de um revestimento com função cosmética (Nano $5 \mathrm{C}$ ) desenvolvido por meio da nanotecnologia com o propósito de oferecer ao tecido as funções de hidratação e redução de medidas e celulite.

As amostras da Dinâmica 3 receberam os seguintes rótulos: Não contém substância nanotecnológica e Contém substância nanotecnológica. Duas amostras de tecidos iguais, entretanto, que receberam beneficiamentos diferentes, foram armazenadas juntas, em sacolas plásticas transparentes e idênticas. 0 objetivo dessa estrutura de pesquisa foi avaliar se os consumidores perceberiam os benefícios gerados com a aplicação da substância desenvolvida por meio da nanotecnologia e avaliar o impacto da informação sobre conteúdo nanotecnológico dos artefatos têxteis na percepção do consumidor (DUTCOSKY, 2013; STONE; SIDEL, 2004). 
Tabela 2 - Rotulagem das amostras do Grupo A

\begin{tabular}{|c|c|}
\hline Conteúdo do rótulo & Características das amostras do Grupo A \\
\hline \multirow{5}{*}{$\begin{array}{l}\text { Tecidos que continham o rótulo Não } \\
\text { contém substância nanotecnológica }\end{array}$} & $\begin{array}{l}\text { Brim misto cedro (tecido sarja Opera stretch LG.) } \\
\text { de cor branca, classificado como tecido plano } \\
\text { com estrutura sarja, composto por } 98 \% \text { de } \\
\text { algodão e } 2 \% \text { de elastano. }\end{array}$ \\
\hline & $\begin{array}{l}\text { Brim cedro de cor marrom claro, classificado } \\
\text { como tecido plano com estrutura de tela estilo } \\
\text { sarja, composto por } 100 \% \text { de algodão. }\end{array}$ \\
\hline & $\begin{array}{l}\text { Jeans misto cedro (tecido índigo misto) de } \\
\text { cor azul, classificado como tecido plano com } \\
\text { estrutura de tela estilo sarja, composto por } 26 \% \\
\text { de algodão, } 72 \% \text { de poliéster e } 2 \% \text { de elastano. }\end{array}$ \\
\hline & $\begin{array}{l}\text { Jeans cedro de cor azul, classificado como tecido } \\
\text { plano com estrutura sarja, composto por } 100 \% \\
\text { de algodão. }\end{array}$ \\
\hline & $\begin{array}{l}\text { Malha supplex de cor preta, classificada como } \\
\text { malha com estrutura por trama, composta por } \\
91 \% \text { de algodão e } 9 \% \text { de supplex. }\end{array}$ \\
\hline
\end{tabular}

\section{Tabela 3 - Rotulagem das amostras do Grupo B}

\begin{tabular}{|l|l|}
\hline Conteúdo do Rótulo & Características das amostras do Grupo B \\
\hline \multirow{5}{*}{$\begin{array}{l}\text { Tecidos que continham o } \\
\text { rótulo Contém substância } \\
\text { nanotecnológica }\end{array}$} & $\begin{array}{l}\text { Brim misto cedro (tecido sarja Opera stretch LG.) } \\
\text { de cor branca, classificado como tecido plano com } \\
\text { estrutura sarja, composto por 98\% de algodão e } \\
2 \% \text { de elastano. }\end{array}$ \\
\cline { 2 - 3 } & $\begin{array}{l}\text { Brim cedro de cor marrom claro, classificado como } \\
\text { tecido plano com estrutura de tela estilo sarja, } \\
\text { composto por 100\% de algodão. }\end{array}$ \\
\cline { 2 - 3 } & $\begin{array}{l}\text { Jeans misto cedro (tecido índigo misto) de cor azul, } \\
\text { classificado como tecido plano com estrutura de } \\
\text { tela estilo sarja, composto por 26\% de algodão, } \\
72 \% \text { de poliéster e 2\% de elastano. }\end{array}$ \\
\cline { 2 - 3 } & $\begin{array}{l}\text { Jeans cedro de cor azul, classificado como tecido } \\
\text { plano com estrutura sarja, composto por 100\% de } \\
\text { algodão. }\end{array}$ \\
\cline { 2 - 3 } & $\begin{array}{l}\text { Malha supplex de cor preta, classificada como } \\
\text { malha com estrutura por trama, composta por } \\
\text { 91\% de algodão e 9\% de supplex. }\end{array}$ \\
\hline
\end{tabular}

Nessa dinâmica, os avaliadores-consumidores escolheram, entre os cinco tipos de tecido, qual gostariam de avaliar. As duas amostras do mesmo tipo de 
tecido escolhido pelos participantes foram entregues ao mesmo tempo para cada pessoa.

Junto com as amostras de tecido, foram entregues fichas contendo orientações, perguntas e espaços para possíveis anotações sobre a análise sensorial dos tecidos. Após finalizar tal atividade, os mediadores fizeram perguntas a respeito da percepção do consumidor sobre o conceito de nanotecnologia, os benefícios associados a ela e a relação entre riscos e benefícios. As perguntas discutidas estão dispostas na Tabela 4.

\section{Tabela 4 - Questionário usados na Dinâmica 3}

\begin{tabular}{|c|c|}
\hline \multicolumn{2}{|c|}{ Questionário } \\
\hline 1 & $\begin{array}{l}\text { Vocês acreditam que alguma das características percebidas durante a análise } \\
\text { sensorial realizada no início desta dinâmica está associada ao desenvolvimento } \\
\text { de tecnologias para tecidos? Se sim, quais são essas características e por quê? }\end{array}$ \\
\hline 2 & $\begin{array}{l}\text { Como vocês acham que a inovação tecnológica poderia melhorar os tecidos que } \\
\text { vocês analisaram? Por quê? }\end{array}$ \\
\hline 3 & $\begin{array}{l}0 \text { que pensam sobre o uso da nanotecnologia para o desenvolvimento de } \\
\text { tecidos? Por quê? }\end{array}$ \\
\hline 4 & $\begin{array}{l}\text { Vocês necessitam de mais informações sobre esses tecidos antes de comprá-los } \\
\text { ou de comprar uma roupa fabricada com eles? Por quê? }\end{array}$ \\
\hline 5 & $\begin{array}{l}\text { Vocês acham que o uso da nanotecnologia para desenvolver tecidos e/ou } \\
\text { roupas pode oferecer benefícios e/ou riscos ao consumidor? Por quê? }\end{array}$ \\
\hline 6 & $\begin{array}{l}\text { A nanotecnologia é o estudo e a manipulação de materiais em escalas } \\
\text { extremamente pequenas (isto é, } 1 \text { nanômetro equivale a } 1 \text { bilionésimo de } \\
\text { metro), que geram estruturas com propriedades significativamente diferentes } \\
\text { das detectadas em escala maior. Para que todos tenham consciência dessa } \\
\text { redução, é possível estabelecer a seguinte relação: a diferença de tamanho } \\
\text { entre uma nanopartícula e uma bola de futebol é a mesma entre uma bola de } \\
\text { futebol e a Terra. } \\
\text { Graças ao estudo dessa tecnologia, é possível fabricar roupas que não sujam, } \\
\text { impermeáveis a água e óleo, com substâncias transparentes para bloquear os } \\
\text { raios ultravioleta e repelir mosquitos, vestuários que proporcionam hidratação } \\
\text { com redução da celulite ou que podem combater bactérias, entre outros } \\
\text { benefícios. É valido ressaltar que as vantagens ocasionadas pela nanotecnologia } \\
\text { não se limitam apenas ao setor de vestuário, mas também servem ao domínio } \\
\text { da indústria de alimento, farmacêutica, eletrônica etc. Contudo, os cientistas } \\
\text { advertem que ainda não é possível estabelecer o impacto que essa tecnologia } \\
\text { poderá causar ao meio ambiente e à saúde dos trabalhadores e consumidores. } \\
\text { Por exemplo, estudos afirmam que algumas nanopartículas podem ser bastante } \\
\text { tóxicas a animais, plantas e pessoas, condição que poderá provocar doenças ou } \\
\text { desequilibrar o ecossistema. } \\
\text { Após receber essas informações, sua opinião sobre nanotecnologia mudou? } \\
\text { Por quê? }\end{array}$ \\
\hline
\end{tabular}

0 tratamento dos dados dessa etapa da pesquisa de campo iniciou-se com a identificação das unidades de registro por temas. De acordo com Bardin (2011, p. 135), "o tema e a unidade de significação que se liberta naturalmente de um texto analisado segundo certos critérios relativos à teoria que serve de guia à leitura". Assim, o contexto nos quais esses temas são interpretados segue os assuntos abordados no levantamento bibliográfico já apresentado.

Para que tais critérios sejam atendidos, a transcrição e a leitura de todos os diálogos do grupo focal foram necessárias como a primeira ação para encontrar o núcleo de sentido das discussões e/ou exposições de opiniões. Por se tratar de uma análise qualitativa, nessa etapa, foi considerada principalmente a presença de um tema específico como regra de enumeração (BARDIN, 2011). 


\section{Resultado e discussões}

0 levantamento bibliográfico demonstrou que a indústria têxtil e de confecção atravessou diferentes processos de transformação resultantes do desenvolvimento de novas tecnologias, que procederam em conjunto de novas funções que alteram o modo como os indivíduos percebem os produtos têxteis e do vestuário com valor de moda.

Adicionalmente, foi possivel perceber que o significado atribuído aos objetos, bem como ao conteúdo nanotecnológico de tecidos e roupas com valor de moda, é construído a partir da associação que os consumidores fazem com experiências vivenciadas em um momento anterior, que não estão apenas ligadas aos artefatos têxteis, mas também a outros objetos presentes na natureza e na sociedade.

Posto isso, a discussão em grupo foi escolhida como instrumento de pesquisa fundamental para explorar o universo dos consumidores com o propósito de entender como eles interpretam o conteúdo nanotecnológico contido em tecidos e roupas com valor de moda. Assim, ao longo do grupo focal, os participantes foram questionados sobre: o conceito de nanotecnologia, os benefícios associados a ela e a relação entre riscos e benefícios.

Em relação à primeira temática, foi identificado que o conteúdo nanotecnológico para os avaliadores-consumidores é: um processo que resultará em meIhoria ou inovação para o produto; tecnologia invisível, matéria-prima que se encontra em uma escala muito pequena que pode ser usada para inovar ou melhorar as caracteristicas de um produto. As respostas apresentadas referem-se, principalmente, aos aspectos tangiveis dessa inovação, os quais podem ser associados às funções indicativas do produto, descritas anteriormente nas considerações sobre o tema apresentadas por Bürdek (2010), Löbach (2001) e Gomes Filho (2006). Assim, a nanotecnologia para o usuário é um instrumento que contribui para a melhoria da qualidade utilitária do produto, como, por exemplo, a oferta de novas funções e/ou de maior eficácia durante a utilização objeto. Sobre essa temática foi relatado que:

Avaliador [A5]: "Eu creio que nanotecnologia seja o processo de botar [aplicar em] uma roupa [...] elasticidade, dri-fit. Eu não sei definir, mas eu já vi exemplos."

Avaliador [A7]: "[...] eu acho que em vez de dar o conceito é mais fácil dar os exemplos. Eu acho que é o que vai te trazer talvez mais elasticidade, uma proteção térmica, uma proteção em relação a raios ultravioleta. Assim, é um tratamento a mais que um tecido tem. Um tratamento."

Avaliador [A8]: "[...] eu acredito que a proposta é que se torne quase que imperceptível para quem tá [...]."

Avaliador [A9]: "Porque nanotecnologia são nanopartículas, não são micropartículas. Incluídas no tecido com um produto pra [para] um melhoramento, um beneficiamento daquele produto."

Depois, quando questionados sobre os benefícios que os tecidos e ou o vestuário poderiam ganhar por causa da nanotecnologia, os participantes do grupo focal mencionaram principalmente aspectos ligados às funções indicativas e estéticas do produto, tais como aumento da resistência, conforto, textura lisa, textura seca, além de elasticidade, proteção térmica, proteção UV e proteção do frio. As- 
sim, mais uma vez, os aspectos tangiveis são fatores fundamentais para expressar a percepção dos consumidores sobre a presença da nanotecnologia nos produtos têxteis com valor de moda.

Entretanto, sabe-se que os aspectos intangiveis como, por exemplo, atitudes, valores e estilo de vida do consumidor, são fundamentais para diferenciação no mercado, escolha e satisfação dos consumidores pelo uso dessa nova tecnologia têxtil. Por esse motivo, investir em novas estratégias que alterem o posicionamento pragmático, ou seja, retirá-lo da orientação exclusivamente técnica, poderá trazer a essa inovação maior aceitação por diferentes públicos consumidores. Dessa forma, o estudo do design é fundamental para o processo de inovação associado ao uso da nanotecnologia em tecidos e vestuário.

Adicionalmente, é possivel afirmar que os aspectos simbólicos dessa inovação são ressaltados com maior facilidade quando são discutidos na sessão sobre a relação entre os riscos e benefícios do uso da nanotecnologia para desenvolver produtos têxteis. Nesse momento, foi destacado pelos participantes que uma das preocupações dos consumidores quando interagem com uma novidade tecnológica é se ela poderá causar riscos para a sociedade ou para o meio ambiente, aspecto que também está relacionado com a responsabilidade social de cada indivíduo.

Os participantes chegaram a associar a nanotecnologia a outras inovações que apresentam problemas e/ou discussões em relação ao impacto ambiental ou à toxicidade dessas sustâncias para as pessoas - mesmo tendo sido feita uma leitura do texto sobre conceito, benefícios e riscos do uso da nanotecnologia pelas mediadoras -, mas também defenderam o investimento em pesquisa e desenvolvimento desse tipo de tecnologia para superar os riscos, conforme pode ser observado a seguir.

Avaliador [A1]: "E eu acho que não é só riscos, é consequência também [...] igual aos alimentos transgênicos. Né?

[...] porque, pelo menos, a minha opinião muda. Porque, além da gente tá trazendo mais uma coisa que pode degradar o meio ambiente e todo o ecossistema, não só animal, mas a gente mesmo quanto ser vivo. É claro que muda. [...] enfim, me sentiria mais resistente a adquirir esse produto."

Avaliador [A2]: "Mas você sabe quais são as consequências? [...] eu defendendo. Num [não] me importo de saber que há um risco porque o ser humano precisa buscar o risco e superar o risco."

Avaliador [A3]: "Então, será que num [não] é melhor. [...] ninguém sabe ainda, pow! Quem sabe isso aí num [não] tá evitando tu ter um câncer de pele daqui a 50 anos."

Avaliador [A6]: "[...] Igual também do xampu que botava urânio pra fazer o cabelo brilhar. Vê aí o que aconteceu! [...] feito a questão do Actvia, que diz: "se não der certo com você, eu devolvo seu dinheiro." Ai a gente pode conversar! É também dizer assim que teve também uma vez que tava [estava] um boato que dizia que tava [estava], que fazia mal, que acabava com a flora intestinal e ele conseguiu desmentir isso também. Ai, pode ser."

Avaliador [A8]: "Toda pesquisa científica, se você for ver registro histórico [...]. Einstein, quando estava bolando a teoria da relatividade, ele também foi criticado, na época não foi aceito. Depois 
de muito tempo, foi que foi visto que foi uma coisa benéfica. Mas então isso não quer dizer que seja uma coisa, exatamente, uma coisa ruim. É uma possibilidade. Tudo na vida é uma possibilidade. [...] mas é pra isso que serve o estudo, né? A pessoa antes de produzir algo desse em grande escala tem que antes passar por um embasamento [...]."

Outro aspecto que deve ser mencionado é que a percepção da responsabilidade sobre os riscos que o governo e/ou a empresa tem em relação ao que é oferecido para os consumidores foi novamente um fator favorável ao consumo.

Avaliador [A8]: "É como eu Ihe respondi. Se fosse uma coisa que fosse avaliada no Estado, que fosse aprovado, que desse todo um respaldo que não iria oferecer nenhum risco, sim! Porque se é liberado para população, eu acredito que antes há uma avaliação rigorosa. Não vai chegar assim, um negócio na doida e: toma aí pra tu! Que tem uma série de impactos."

Portanto, segundo os entrevistados, a nanotecnologia aplicada aos artefatos têxteis deverá exigir mais responsabilidade por parte dos fabricantes e consumidores e maior qualidade do produto, além de estimular o desenvolvimento de constantes pesquisas com o propósito de melhorar e diversificar o uso da tecnologia em têxteis, sem causar danos ao usuário e ao meio ambiente. Essas opiniões só legitimam as afirmações apresentadas por autores como Itama (2015), Cruz (2014), Terra, Batista e Almeida (2010) e Manzini (2008), que indicam que 0 comportamento do consumidor diante das inovações e da produção de bens será guiado, cada vez mais, pelos cuidados com o meio ambiente e a sociedade. Esse fato ressalta igualmente a importância de projetar artefatos que conciliem inovações práticas e estéticas com os elementos socioculturais do usuário, conforme recomendaram Bürdek (2012) e Löbach (2001).

\section{Considerações finais}

A compreensão do universo pesquisado foi fundamental para extrair informações que poderão ser usadas, posteriormente, no desenvolvimento de estratégias de comunicação dos significados que uma inovação tecnológica deverá ter para o consumidor, visto que foi igualmente esclarecido que a escolha e a preferência por um artefato específico não depende apenas do bom desempenho prático do produto, mas também dos sentidos que lhe são atribuídos.

Apesar disso, sabe-se, que os significados de um artefato e as funções que desempenham no cotidiano das pessoas são constantemente modificados, além de diversificados à medida que são usados e interpretados segundo a experiência, a necessidade e a cultura de cada indivíduo ou sociedade. Apesar disso, é necessário considerar que a efemeridade dos significados atribuídos pelos consumidores aos objetos torna o desenvolvimento de produtos uma atividade complexa, pois os motivos que direcionam o processo de inovação podem ser alterados de forma vertiginosa.

0 estudo demonstrou que a nanotecnologia é percebida, principalmente, como recurso técnico que poderá ofertar novos benefícios para o artefato têxtil, entretanto, a sua implementação poderá ser associada a incertezas relacionadas ao impacto ao meio ambiente e à sociedade, bem como à necessidade de constante investigação e fiscalização sobre o seu uso pela indústria. Sendo assim, constata-se, nos últimos anos, a visão de que o desenvolvimento só ocorre de fato por meio do progresso mútuo de todos os setores de um país que vem ganhando força, mas é inevitável considerar igualmente que um cenário social bem 
estruturado facilita e estimula a inovação, um dos requisitos primordiais para a renovação do mercado e a expansão do sistema econômico vigente. Porém, nem os avanços ligados ao social nem ao setor econômico por meio da pesquisa e do desenvolvimento da nanotecnologia são, atualmente, atividades simples porque as políticas públicas do Estado brasileiro com a temática ainda estão em fase embrionária, e a conscientização do mercado sobre essa perspectiva manifesta-se de maneira mínima.

Posto isso, é possivel afirmar que este estudo cumpre seu objetivo à medida que consegue obter informações que identificam a opinião dos consumidores sobre o conteúdo nanotecnológico de tecidos e roupas com valor de moda, ao mesmo tempo que reúne e apresenta as principais opiniões dos consumidores sobre esse tipo de tecnologia. Todavia, ele encerra recomendando que sejam realizadas não só novas pesquisas, visando medir a abrangência da perspectiva dos significados identificados sobre o conteúdo nanotecnológico, como também investigações sobre os impactos (riscos e beneficios) que a nanotecnologia, quando aplicada em têxteis com valor de moda, pode causar na vida cotidiana dos consumidores. Por fim, sobre este último aspecto, deverá ser considerado o ciclo de produção desses artefatos, os quais só poderão ser associados ao processo de desenvolvimento se desempenhados com responsabilidade.

\section{Agradecimentos}

Agradecemos à Coordenação de Aperfeiçoamento de Pessoal de Nivel Superior, CAPES, Brasil, pela concessão de bolsa de mestrado de um dos autores durante a realização desta pesquisa.

Recebido em: 02/01/2017

Aprovado em: 21/01/2017 


\section{NOTAS}

[1] Forças intermoleculares que permitem às moléculas conter a propriedade inespecífica de repelência ou atração (IUPAC, 2014).

${ }^{[2]}$ Electrospinning é um processo que utiliza um campo elétrico para atrair uma solução de polimero carregada positivamente por meio de uma agulha com diâmetro capilar. Assim, o jato emerge na base do bocal, em seguida a substância viaja até se dividir em muitas fibras na região de espalhamento, local onde a solução se solidifica criando uma camada de fibras interligadas denominadas de não-tecidos (STEPANYAN et al., 2014).

${ }^{[3]}$ Tradução livre de: "[...] any change, of permanent consequences, in the organization and/or production way faced by a social group" (ARRILLAGA; GAND; RAMÍREZ, 2013, p. 122).

${ }^{[4]}$ Substância desenvolvida por meio da nanotecnologia com efeito cosmético, voltado para a redução de celulite.

\section{REFERÊNCIAS}

AHMED, Nahed S. E.; EL-SHISHTAWY, Reda. M. The use of new technologies in coloration of textile fibers. In: Journal of Materials Science. [S.I.], vol. 45, n. 5, pp. 1143-1153, 22 dez. 2010.

ALMEIDA, Ana. Efeito Lótus. Porto: Universidade do Porto, 2012. Disponivel em: <http://paginas.fe.up. pt/ projfeup/cd_2012_13/files/REL_0101_02.PDF>. Acesso em: 20 dez. 2015.

APEL, Petra; DUBBERT, Wolfgang; SCHWIRN, Katrin; VÖLKER, Doris; WINDE, Christine; ZIETLOW, Brigitte. Use of nanomaterials in textiles. Dessau - Roßlau: Umweltbundesamt, 2013. Disponivel em: <https:// www.umweltbundesamt.de/sites/default/files/medien/376/publikationen/datenblatt_nanoprdukte_ textilien_e.pdf $>$. Acesso em: 29 nov. 2015.

ARRILLAGA, Hugo.; GRAND, Lucila.; RAMÍREZ, Natalia. The evaluation of innovation processes from the perspective of territorial development. In: Journal of Technology Management \&t Innovation. [S.I.], pp. 118-130, fev. 2013. Disponivel em: <http://www.scielo.cl/pdf/jotmi/v8s1/art40.pdf>. Acesso em: 22 nov. 2015.

BARBOUR, Rosaline. Grupos focais. Porto Alegre: Artmed, 2009.

BARDIN, Laurence. Análise de conteúdo. São Paulo: Edições 70, 2011.

BERGER, Peter. L; LUCKMANN, Thomas. A construção social da realidade: um livro sobre sociologia do conhecimento. Lisboa: Dinalivro, 2004.

BROASCA, Gianina.; BORCIA, Gabriela; DUMITRASCU, Nicoleta; VRINCEANU; Narcisa. Characterization of ZnO coated polyester fabrics for UV protection. Applied Surface Science. [S.I.], pp. 272-278, 15 abr. 2013.

BÜRDEK, Bernhard E. Design: história, teoria e prática do design de produtos. São Paulo: Blucher, 2010.

CARDOSO, Rafael. Design para um mundo complexo. São Paulo: Cosac Naify, 2012.

COLCHESTER, Chloë. Textiles today, a global survey of trends and traditions. London: Thames and Hudson, 2007.

CRESWELL, John W. Research design: qualitative, quantitative, and mixed method approaches. Lincoln: SAGE Publications, 2013.

CRUZ, Daniel Nery da. Algumas caracteristicas da pós-modernidade na concepção de Gilles Lipovetsky. Intuitio, vol. 6, n. 1, pp. 79-95. 2013. Disponivel em: <http://revistaseletronicas.pucrs.br/civitas/ojs/index. php/intuitio/article/download/13133/9381 >. Acesso em: 30 mar. 2014.

SILVERMAN, David. Interpretação de dados qualitativos: métodos para análise de entrevistas, textos e interações. Porto Alegre: Artmed, 2009.

DENG, Hui; ZHANG, Hongda. In situ synthesis and hydrothermal crystallization of nanoanatase TiO 2 -SiO 2 coating on aramidf abric (HTiSiAF) for UV protection. In: Microscopy Research and Technique. [S.I.], vol. 78, n. 10, pp. 918-925, 25 ago. 2015. Disponivel em: <http://api.wiley.com/onlinelibrary/tdm/v1/ articles/10.1002/jemt.22556>. Acesso em: 3 dez. 2015.

DIACONU, Mihaela. Technological innovation: concept, process, typology and implications in the economy. Theoretical and Applied Economics. [S.I.], vol. 18, n. 10, pp. 127-144, 2011. Disponivel em: <http://store. ectap.ro/articole/ 655.pdfs. Acesso em: 21 nov. 2015.

DUTCOSKY, Silvia Deboni. Análise sensorial de alimentos. Curitiba: Champagnat, 2013.

ENGEL, James F; BLACKWELL, Roger D.; MINIARD, Paul W. 0 comportamento do consumidor. Rio de Janeiro: LTC, 2000. 
FELICE, Fabio de; PETRILLO, Antonella. Key success factors for organizational innovation in the fashion industry. International Journal of Engineering Business Management. [S.I.], vol. 5, n. 27, pp. 1-11, jul. 2013

FERREIRA, Lúcia Marisa Vieira. Revestimento hidrofóbico. 2013. 57 f. Dissertação (Mestrado) - Curso de Engenharia de Materiais, Faculdade de Ciências e Tecnologia, Lisboa, 2012.

FILIPPONI, Luisa; SUTHERLAND, Duncan. Nanotechnologies: principles, applications, implications and hands-on activities: A compendium for educators. Luxembourg: European Commission, 2012. Disponivel em: <https://ec.europa.eu/research/industrial_technologies/pdf/nano-hands-on-activities_en.pdfs. Acesso em: 28 nov. 2015.

FLAIN, Valdirene Silveira. A nanotecnologia e o direito do consumidor à informação: perspectivas de proteção na sociedade de risco. Revista da Faculdade Mineira de Direito. [S.I], vol. 14, n. 28, pp. 31-52, jul. 2011.

FLICK, Uwe. Qualidade na pesquisa qualitativa. Porto Alegre: Artmed, 2009.

FLÜGEL, John. Carl. A psicologia das roupas. São Paulo, SP: Mestre Jou, 1966.

FRINGS, Gini. Stephens. Moda: do conceito ao consumidor. Rio de Janeiro: Bookman, 2012.

GILL, Antonio Carlos. Métodos e técnicas da pesquisa social. São Paulo: Atlas, 1987.

GOMES FILHO, João. Design do objeto: bases conceituais. São Paulo: Escrituras, 2006.

GONDIM, Sônia Maria Guedes. Grupos focais como técnica de investigação qualitativa: desafios metodológicos. Paideia (Ribeirão Preto), Ribeirão Preto, v. 12, n. 24, pp. 149-162, 2002.

HOSSAIN, Milon; BISWAS, Ahsanul Karim; PARVEZ, Shohan; BAIN, Sudipta. Advanced functionalization of textiles by nanofinishing: a review. International Conference on Mechanical, Industrial and Materials Engineering. Rajshahi, vol. 3, n. 1, pp. 503-507, nov. 2013.

IBGE. Instituto Brasileiro de Geografia e Estatística. Censo Demográfico. Rio de Janeiro: IBGE, 2010.

ITMA. Technologies powering textile innovation. Disponivel em: $<$ http://www.itma.com/docs/defaultsource/downloads/nwtt-brochure/ itma_nwtt_bro.pdf?sfursn=2>. Acesso em: 24 nov. 2015.

JOSHI, Mangala.; BHATTACHARYYA, Anita. Nanotechnology: a new route to high performance functional textiles. Textile Progress. [S.I.], vol. 43, n. 3, pp. 155-233, set. 2011. Informa UK Limited.

LAVER, James. A roupa e a moda. São Paulo: Companhia das Letras. 1990.

LESSA, Sergio. Mundo dos homens: trabalho e ser social. São Paulo: Instituto Lukács, 2012.

LIMA, Mayana. Virginia. Viegas.; STEINER NETO, Pedro José. A qualidade percebida, os valores de consumo e as emoções como antecedentes da satisfação de usuários de Shopping Center: a construção de um modelo de equações estruturais. Revista Brasileira de Administração Científica, Aquidabã, vol. 5, n. 1, pp. $6181,2014$.

LIPOVETSKY, Gilles. 0 império do efêmero: a moda e seus destinos nas sociedades modernas. São Paulo: Companhia da Letras, 2009.

LÖBACH, Bernd. Design industrial: bases para a configuração dos produtos industriais, São Paulo: Edgard Blücher, 2001.

LST: LIETUVOS STANDARTIZACIJOS DEPARTAMENTAS. ISO/TS 80004-4:2011: Nanotechologies Vocabulary - Part 4: Nanostructuredmaterials. [S.I.]: Lietuvos Standartizacijos Departamentas, 2015. Disponivel em: <http://www.Isd.It/standards/StandardPreviewDoc/648602_EN.pdf>. Acesso em: 29 nov. 2015.

MANZINI, Ezio. Design para inovação social e sustentabilidade: comunidades criativas, organizações colaborativas e novas redes projetais. Rio de Janeiro: E-papers, 2008.

MEDEIROS, Eliton S.; PATERNO, Leonardo G.; MATTOSO, Luiz H. C. Nanotecnologia. In: DURÁN, Nelson; MATTOSO, Luiz Henrique Capparelli; MORAIS, Paulo Cezar de. Nanotecnologia: Introdução, preparação e caracterização de nanomateriais e exemplos de aplicação. São Paulo: Artliber, 2006. pp. 13-29.

NIEMEYER, Lucy. Elementos de semiótica aplicada ao design. Rio de Janeiro: 2AB, 2009.

NORMAN, Donald A. Design emocional: por que adoramos (ou detestamos) os objetos do dia-a-dia. Rio de Janeiro: Rocco, 2008 
PEZ7OLO, Dinah Bueno. Tecidos: história, trama, tipos e uso. São Paulo: SENAC / São Paulo, 2007.

QUEIROZ, Julia Atroch.; COUTINHO, Solange Galvão; ROCHA, Maria Alice Vasconcelos. 0 design da informação no processo de inovação das indústrias têxtil e do vestuário. In: Congresso Internacional de Design da Informação, 2013, Recife. Anais do CIDI 2013. Recife: UFPE, 2013.

PATRA, Jayanta Kumar .; GOUDA, Sushanto. Application of nanotechnology in textile engineering: An overview. Journal of Engineering and Technology Research, vol.5, n. 5, pp. 104-111. jun. 2013. Disponivel em: <http://www.academicjournals.org/ journal/JETR/article-full-text-pdf/04977A52454>. Acesso em: 29 nov. 2015.

RESSEL, Lúcia Beatriz; BECK, Carmen Lúcia Colomé; GUALDA, Dulce Maria Rosa; HOFFMANN, Izabel Cristina; SILVA, Rosângela Marion da; SEHNEM, Graciela Dutra, 0 uso do grupo focal em pesquisa qualitativa. Texto \&t Contexto. Enfermagem JCR, vol. 17, pp. 779-786, 2008.

ROCHA, Maria Alice Vasconcelos. Moda e sustentabilidade: combinação possivel? In: VI Encontro Naciona de Estudos do Consumo/ II Encontro Luso-Brasileiro de Estudos do Consumo, 2012, Rio de Janeiro. Anais do VI ENEC / II ELBEC. Rio de Janeiro: ESPM-RJ, 2012.

. Conexões conceituais entre moda, vestuário, design e arte. In: CAMPOS, G. B.; SILVA, J. (orgs.). Design, Arte, Moda e Tecnologia. São Paulo: Rosari, Universidade Anhembi Morumbi, PUC-Rio e UnespBauru, 2010, pp. 1-12.

. Contribuições ao desenvolvimento de uma metodologia para a caracterização do comportamento do consumidor da indústria do vestuário: uma abordagem segundo Maslow. 1999. Mestrado em Engenharia de Produção. Universidade Federal de Pernambuco. Pernambuco, 1999.

ROSA, Aline Barriquello; COSTA, Mylena Cristina Dornellas da. Nanotecnologia e cosmética: utilização conceitos, efeitos, beneficios e cuidados necessários. In: CONGRESSO MULTIPROFICIONAL EM SAÚDE, 6, 2012, [S.I.]. Anais eletrônicos. 2012. pp. 1-3. Disponível em: <http://www.unifil.br/portal/arquivos/ publicacoes/paginas/2012/8/485_759_publi pg.pdf . Acesso em: 5 jan. 2016.

SALCEDO, Elena. Moda ética para um futuro sustentável. 2012. 57 f. São Paulo: Gustavo Gili, 2014.

SANTOS, Cláudia Maria Pereira dos. Nanoencapsulação de ingredientes activos em cosmetologia. Dissertação (Mestrado Integrado em Ciências Farmacêuticas) - Universidade Fernando Pessoa. Porto, 2012.

SEIVEWRIGHT, Simon. Fundamentos de design de moda: pesquisa e design. Porto Alegre: Bookman, 2012

SAWHNEY, Amar Paul Singh; CONDON, Brian; SINGH, Kanwar Vikas; PANG, Su-Seng; LI, Guogiang. Modern applications of nanotechnology in textiles. In: Textile Research Journal. Los Angeles, pp. 731-739, jan. 2008.

SENAI-SP. Nanomundo: um universo de descobertas e possibilidades. São Paulo: SENAI-SP, 2013.

SOLOMON, Michael R. 0 comportamento do consumidor: comprando consumindo e sendo. Porto Alegre: Bookman, 2011.

SOLOMON, Michael R.; RABOLT, Nancy. J. Consumer behaviour in fashion. Upper Saddle River, NJ: Prentice Hall, 2004

STEPANYAN, Roman; SUBBOTIN, Andrey; CUPERUS, Louise; BOONEN, Matthew; DORSCHU, Marko; OOSTERLINCK, Filip.; BULTERS, Markus. Fiber diameter control in electrospinning. In: Applied Physics Letters, vol. 105, n. 17, pp. 1-4, 27 out. 2014. AIP Publishing. DOI: 10.1063/1.4900778. Disponivel em: <http://scitation-aip-org.ez19.periodicos.capes.gov.br/docserver/fulltext/aip/journal/apl/105/17/1.4900778. xpires=1448948895Ctid=id\&taccname=2112785\&tchecksum=28EDCDAB37417507771B07BC897CAF07> Acesso em: 1 dez. 2015

STONE, Herbert; SIDEL, Joel. Sensory evaluation practices. Redwood City: Elsevier, 2004

TERRA, Branca; BATISTA, Luiz Albert; ALMEIDA, Mariza. Inovação e sociedade. Polêmica, vol. 9, n. 4, pp. 82-87, out/dez. 2010. Disponível em: <http://www.e-publicacoes.uerj.br/index.php/polemica/article/ viewFile/2823/1950>. Acesso em: 6 fev. 14.

TREPTOW, Doris. Inventando moda: planejamento de coleção. Brusque: D. Treptow, 2007.

UDALE, Jenny. Fundamentos de design de moda: tecidos e moda. Porto Alegre: Bookman, 2009.

WINDLER, Lena; HEIGHT, Murray; NOWACK, Bernd. Comparative evaluation of antimicrobials for textile applications. Environment International, vol.53, pp. 62-73, jan. 2013. Disponivel em: <http:// ac.els-cdn.com.ez19.periodicos. capes.gov.br/S0160412012002656/1-s2.0-S0160412012002656main.pdf?_tid=3b51f316-988f-11e5-9ff1-00000aab0f26Ctacdnat=1449017844 8453b71f5b0c61416d0bbb86d85284ec>. Acesso em: 1 dez. 2015.

ZILLE, Andrea; ALMEIDA, Luís; AMORIM, Teresa; CARNEIRO, Noémia; ESTEVES, Maria Fátima; SILVA, Carla $\mathrm{J}$; SOUTO, António Pedro. Application of nanotechnology in antimicrobial finishing of biomedical textiles. Materials Research Express. [S.I.], v. 1, n. 3, pp. 1-28, 1 set. 2014. Disponivel em: <http://iopscience.iop.org/ article/10.1088/20531591/1/3/032003/pdf . Acesso em: 1 dez. 2015. 